\title{
The Meridional Thermospheric Neutral Wind Measured by Radar and Optical Techniques in the Auroral Region
}

\author{
VINCENT B. WICKWAR \\ SRI International, Menlo Park, California \\ John W. Meriwether, Jr., Paul B. Hays, and Andrew F. Nagy \\ Space Physics Research Laboratory, University of Michigan, Ann Arbor
}

\begin{abstract}
Radar observations of ion velocities in the magnetic zenith over Chatanika, Alaska, were used to determine the geomagnetic meridional component of the thermospheric neutral wind. Corrections for molecular diffusion and molecular ion contamination of the pure $\mathrm{O}^{+}$composition assumed for the ionosphere were included in the analysis. Comparison of the averaged diurnal variation of the meridional wind showed good agreement between the two measurement techniques. Good agreement was also found for several cases of simultaneous observations. The evidence suggested that differences were caused by gravity waves. The 7 years of radar meridional wind results were examined with respect to magnetic activity, solar cycle phase, and season. During the day, the meridional component is poleward with a maximum of about $65 \mathrm{~m} / \mathrm{s}$ between 1400 and 1600 local time. During the night, the wind is equatorward with a maximum of about $175 \mathrm{~m} / \mathrm{s}$ between 0200 and 0500 local time. This maximum occurs after local magnetic midnight, which is about 0130 local time. When the neutral wind is averaged for 24 hours, there is a large net equatorward flow. During periods of increased magnetic activity, the nighttime wind between 2300 and 0600 local time becomes stronger toward the equator. The average increase between 0200 and 0600 local time is about $100 \mathrm{~m} / \mathrm{s}$; however, on individual days it can be as large as $400 \mathrm{~m} / \mathrm{s}$. These data pertain mostly to equinox, but the few summer and winter observations in the data set differ in the manner predicted by theory. Comparison of these results with theoretical models shows good agreement at most times, but suggests possible heating poleward of Chatanika during the morning hours. Observed exospheric temperature increases support this hypothesis.
\end{abstract}

\section{INTRODUCTION}

The early models describing transport in the earth's thermosphere predicted the neutral winds would be driven by a pressure gradient directed away from the daytime pressure bulge [King-Hele and Allan, 1966; Geisler, 1967; Dickinson et al., 1968]. The actual findings, however, reported by Stoffregen [1972], Meriwether et al. [1973], Nagy et al. [1974], Hays et al. [1979] and Heppner and Miller [1982] based on the techniques of barium cloud releases and Fabry-Perot interferometry showed the direction of these winds at high latitudes was contrary to these theoretical expectations. These measurements pointed to the importance of ion convection within the auroral region and polar cap in modifying the solar-driven flow. Recent numerical models on the thermospheric general circulation described by Rees et al. [1980], Dickinson et al. [1981], Fuller-Rowell and Rees [1981], and Roble et al. [1982, 1983] reflect the revisions of the early understanding of thermospheric dynamics that have emerged once the importance of high latitude heating and momentum transfer from ions in motion to the neutral atmosphere in the dynamics of the high latitude thermosphere became known. The reviews by Straus [1978], Mayr et al. [1978], Mayr and Harris [1979], Hernandez and Roble [1979], and Meriwether [1983] provide further details on the reworking of the theoretical framework.

The measurements of thermospheric winds by instrumentation on board the Dynamics Explorer B satellite [Hoffman and Schmerling, 1981; Hays et al., 1981; Killeen et al., 1982; Rees et al., 1982; Killeen et al., 1983; Spencer et al., 1981, 1982;

Copyright 1984 by the American Geophysical Union.

Paper number 4A1083.

0148-0227/84/004A-1083\$05.00
Hays et al., 1984] should result in further improvements of the thermospheric global circulation model (TGCM) formulation for the physics of high latitude dynamics.

There remains, however, a dearth of ground-based measurements of geomagnetic meridional and zonal thermospheric winds with good temporal resolution at high latitudes. These measurements are an important part of the experimental tests required to examine the validity of the comprehensive threedimensional TGCM model results. These ground-based observations provide information on the diurnal variation of the $F$ region neutral wind within the auroral convection zone. These observations greatly complement the global latitudinal sampling of thermospheric winds by the DE-B satellite.

The geomagnetic meridional component of the thermospheric neutral wind may be calculated from Chatanika incoherent-scatter radar observations of field-aligned ion motions. Because the Chatanika radar could observe the magnetic zenith directly, the need to correct for horizontal transport caused by $E \times B$ drifts is avoided. Observations obtained during the 10 years that the radar was operational at Chatanika resulted in the formation of a data set that may be applied to study the behavior of the thermospheric neutral wind under varying conditions.

In making any measurement with complicated apparatus, comparing the results obtained by the different methods is always advantageous. Such comparisons enable testing the assumptions that are not common to the different methods. Accordingly, as a part of our study, we carry out a comparison between meridional winds derived from radar observations of ion motions and direct measurements made by the FabryPerot interferometer, which was installed and operated by the Michigan Airglow Observatory (MAO) during the late winter months in 1972 and 1973. 
In the appendix, we present the theory for the analysis of the radar data that derives the geomagnetic meridional component of the neutral wind from the measured field-aligned ion velocity. The averaged results obtained from measurements taken between 1971 and 1978 are compared with the averaged Fabry-Perot data. In addition, cases of simultaneous observations are examined. Both means of comparison showed good agreement between the two different techniques. Components of the two data sets in regard to magnetic activity and season were found similar. We, then, examine the more extensive radar data base for variations caused by changes in magnetic activity, solar cycle phase, and season and compare these results with theoretical model calculations.

\section{Determination of the $\boldsymbol{F}$ Region Magnetic Meridional COMPONENT FROM INCOHERENT-SCATTER RADAR OBSERVATIONS}

The geomagnetic meridional component of the thermospheric neutral wind is determined by the radar from measurements of the Doppler shift of the ion spectrum at several altitudes within the $F$ region. These observations may be made throughout the day and, if the $F$ region electron density is sufficiently high, during the nighttime hours as well. The ions have a component of velocity parallel to the magnetic field because of ion-neutral diffusion and because of collisions with neutrals that have a velocity component toward the south or north in the magnetic meridian, which forces ions up or down the field line, respectively.

A correction of the measured ion velocity for ion diffusion is necessary in these calculations to determine the meridional wind; the theoretical basis is provided in the appendix. For the lower range gates, i.e., from 170 to $280 \mathrm{~km}$, this correction turns out to be small. The other range gates required more substantial adjustments, and the signal-to-noise ratio for these gates is smaller; therefore, they are not included in the meridional wind study at this time.

Because we deal normally with the lower range gates, we have to consider the effect of a mixture of atomic and molecular ions. Fortunately, as discussed in the first subsection of the appendix, the difference in diffusion velocities is small at these low altitudes. The equation used in our analysis is (A14) of the appendix. To the extent possible we apply measured quantities to evaluate the terms in this equation. However, the uncertainties are such in the temperature measurements available that we find it advantageous to use model temperature profiles.

We also note that in the interest of having good data, we have restricted the data set to those experiments when the radar was pointed toward magnetic zenith for extensive periods of time or to those experiments where one observing position was frequently in this direction. The resultant temporal resolution is between 2 and $10 \mathrm{~min}$.

\section{Measurements of the Meridional Wind With THE FABRY-PEROT INTERFEROMETER}

The application of the Fabry-Perot interferometer (FPI) to the measurement of the line-of-sight speed of the thermosphere was first carried out by Armstrong [1969] and extended by Hays and Roble [1971b]. This technique has since flourished and the ensuing work has been reviewed by Hernandez and Roble [1979], Hernandez [1980], and Meriwether [1983]. The Fabry-Perot neutral wind measurement, although restricted to the nighttime, is more direct in the sense that the line-of-sight speed is inferred from the observed Doppler shift of the $6300-\AA$ emission of atomic oxygen, excited by dissociative recombination or by energetic particle precipitation. These results, however, are weighted by the volume emission profile of the source emission along the line of sight, which is usually not known. The lifetime of the oxygen atom is sufficiently long for thermalization [Schmitt et al., 1981, 1982], and the observed Doppler shift is taken to be representative of the general atmospheric motion.

The $6300-\AA$ emission in the auroral region may arise either from dissociative recombination [Wickwar et al., 1980; Cogger et al., 1980] with the peak emission near $250 \mathrm{~km}$ or from auroral processes induced by energetic and secondary electrons [Rees, 1969; Roble and Rees, 1977; Sharp et al., 1983] with the peak emission between 180 and $225 \mathrm{~km}$. That these measurements are integrated over a range of altitudes generally has little or no impact because the altitude gradients of the horizontal velocity in this region are usually not very large, as shown by barium cloud and trimethyl aluminum (TMA) trail releases [Meriwether et al., 1973; Heppner and Miller, 1982] and by the Fabry-Perot results obtained from the DE-B satellite [Hays et al., 1981; Killeen et al., 1982, 1983; Hays et al., 1984].

The optical measurements in this paper were made by the 15-cm Fabry-Perot interferometer in the Michigan Airglow Observatory while located at the Ester Dome Observatory (managed by the Geophysical Institute of the University of Alaska) between 1971 and 1975. The instrument as used in 1972 is described by Hays and Roble [1971b] and Hays et al. [1979], and averaged results for observations obtained in the three months of January, February, and March 1972 were published by Hays et al. [1979].

The 1972 observations used a tilting filter photometer with a $1.0^{\circ}$ field of view to monitor the $6300-\AA$ intensity fluctuations. The filter was placed at the tilt angle that best optimized the transmission of $6300-\AA$ emission. The mirror systems for both the Fabry-Perot and this photometer were absolutely calibrated within a precision of $0.2^{\circ}$ so the possible positioning error from the misalignment of the two systems would be about $2 \mathrm{~km}$ at $F$ region heights for zenith measurements.

In the 1973 work, a separate fixed filter photometer was constructed and boresighted with the Fabry-Perot instrument so that the possible alignment error was reduced to $0.04^{\circ}$. The field of view of this instrument was matched to the FabryPerot field of view. The observed Fabry-Perot count rates were normalized by the photometer count rates; this set of ratios was used for data analysis. Further details relating to the instrument and the analysis procedures are provided in the second section of the appendix.

The determination of the reference zero for the observations was deduced from a combination of observations of $6300-\AA$ emissions in the zenith and of the argon emission line at $6296.8739 \AA$. A separate filter was used for the argon emission so that the filter transmission was constant across the Doppler profile of the source. The displacement between the zenith position and the argon position was measured at the beginning of the night's observations and repeated throughout the night. Zenith position observations were made more frequently as a part of the cycle of wind field sampling. These measurements were used to determine the instrumental drift. Numerous argon stability tests have shown the typical drift to be less than $100 \mathrm{~m} / \mathrm{s}$ per night, and the drift occurred slowly over many hours. On occasion short-term shifts in the zenith reference were observed that did not appear in the argon sta- 
bility measurements. These we interpret as arising from vertical velocities associated with gravity wave events [Richmond, 1978, 1979] and will be discussed in a separate paper. The position measurements in the various directions $(\mathrm{N}, \mathrm{S}, \mathrm{E}$, and W) were compared with the instrumental reference to compute the horizontal neutral wind components in the geomagnetic zonal and meridional directions.

The observer varied the integration time chosen for these observations and the values ranged from a minimum of $20 \mathrm{~s}$ for active aurora to $100 \mathrm{~s}$ for times of weak emission. A delay in the onset of integration of $8 \mathrm{~s}$ in the 1973 observations provided time for thermal recovery for each step position. In general, the precision achieved for the 1973 observations was about $\pm 20 \mathrm{~m} / \mathrm{s}$.

The work described by Abreu et al. [1983] has shown there may be a problem in the analysis of Fabry-Perot observations if care is not taken for possible contamination of the observed source emission by scattered light that originates in the adjacent or opposite quadrants. The data selected for comparison with the radar observations were generally those with northward orientation, i.e., toward the brightest quadrant. In general the $6300-\AA$ illumination during auroral activity was widespread over the northern half of the area observed. Moreover, the observations were made for clear skies with a dry and cold troposphere for which the aerosol content is below nominal levels.

\section{Comparison of Meridional Wind Measurements} By THE RADAR AND FABry-PEROT TeChNiQUES

The two instruments were separated by a distance of $38 \mathrm{~km}$. Figure 1 shows the typical observing geometries used for the two instruments. The radar observations were directed toward magnetic zenith and the Fabry-Perot field of view was oriented manually either to the magnetic north or to the magnetic south at a zenith angle of $60^{\circ}$. At $200-\mathrm{km}$ altitude in the lower $F$ region, the spatial separation between the sky regions viewed by the two instruments was about $400 \mathrm{~km}$ and $300 \mathrm{~km}$ for the north and south measurements, respectively.

Figure 2 shows the averaged meridional winds observed by the Fabry-Perot in the 1972 and 1973 periods (Table 1). Figure 2 also shows the averaged meridional wind determined from radar observations between 1971 and 1978 (Table 2). The Fabry-Perot averages were obtained near the vernal equinox. The radar data were also largely dominated by observations made near both equinoxes.

Comparison of the averaged meridional wind curves for the two instruments for 1973 shows good agreement. However, the 1972 averaged Fabry-Perot curve shows a difference of about $50 \mathrm{~m} / \mathrm{s}$ in amplitude when compared with the other two

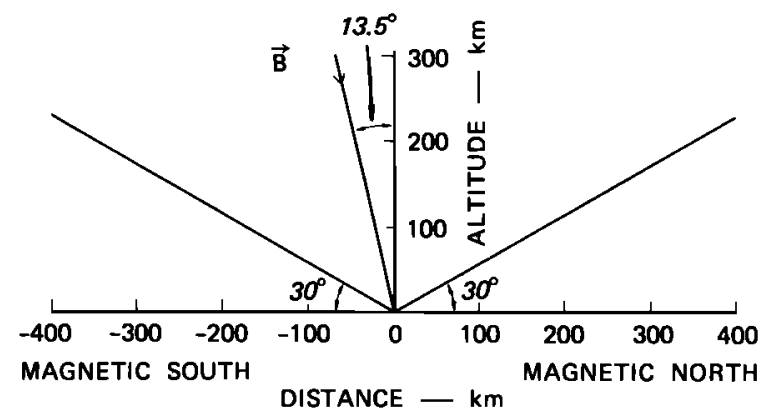

Fig. 1. Comparison of look angles for the radar and Fabry-Perot interferometer.

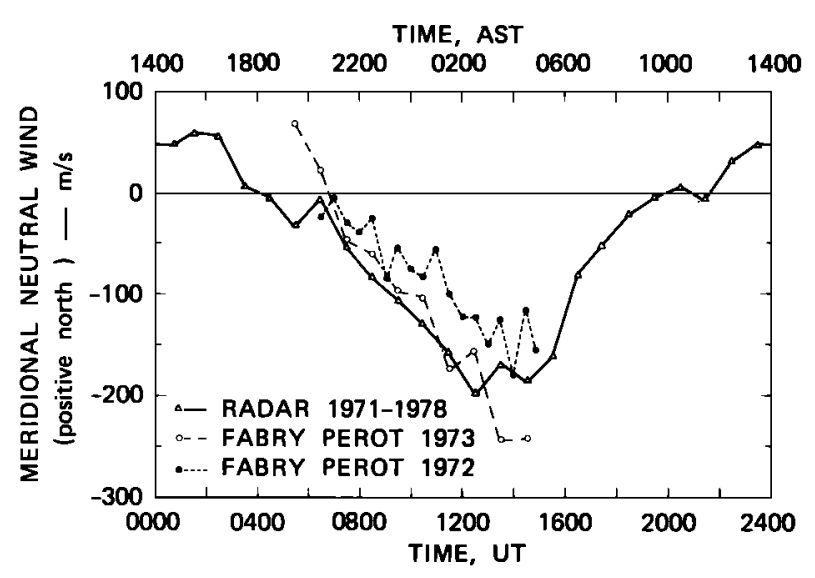

F1g. 2. Comparison of mean meridional winds from the radar data and from the Fabry-Perot interferometer.

curves. To decide whether this good agreement is significant, we need to ascertain that possible differences between the data sets, due to such factors as altitude, magnetic activity, solar cycle phase, and season, are not significant.

In Figure 3, we show mean values for the meridional component based on one-hour averages of the radar data for range gates corresponding to altitudes of 170,225 , and 280 $\mathrm{km}$. The mean curve is determined from these three curves weighted by the number of observations. During the night-

TABLE 1. Dates of Fabry-Perot Observations Along With Geomagnetic and Solar Activity Parameters

\begin{tabular}{|c|c|c|c|c|}
\hline Day & Date, UT & $\Sigma K p$ & $A p$ & $S_{107}$ \\
\hline \multicolumn{5}{|c|}{1972} \\
\hline 1 & Jan. 22 & 30 & 25 & 123.2 \\
\hline 2 & Jan. 23 & 33 & 32 & 136.3 \\
\hline 3 & Jan. 25 & 25 & 17 & 131.8 \\
\hline 4 & Feb. 3 & 16 & 9 & 104.8 \\
\hline 5 & Feb. 14 & $23-$ & 15 & 136.7 \\
\hline 6 & Feb. 15 & $21-$ & 13 & 145.8 \\
\hline 7 & Feb. 17 & 26 & 22 & 168.2 \\
\hline 8 & Feb. 18 & 16 & 12 & 184.4 \\
\hline 9 & Feb. 19 & 19 & 14 & 190.6 \\
\hline 10 & Feb. 25 & 24 & 16 & 151.9 \\
\hline 11 & Feb. 28 & $11+$ & 6 & 133.2 \\
\hline 12 & March 2 & $18+$ & 10 & 129.7 \\
\hline 13 & March 3 & 24 & 16 & 131.1 \\
\hline 14 & March 4 & 15 & 8 & 137.1 \\
\hline is & March 6 & $19+$ & 26 & 145.9 \\
\hline 16 & March 7 & $37-$ & 45 & 143.3 \\
\hline 17 & March 9 & $19-$ & 10 & 137.4 \\
\hline \multicolumn{5}{|c|}{1973} \\
\hline 18 & Feb. 23 & 40 & 48 & 91.4 \\
\hline 19 & Feb. 24 & $42-$ & 54 & 93.6 \\
\hline 20 & Feb. 25 & 33 & 31 & 97.2 \\
\hline 21 & Feb. 26 & $35-$ & 34 & 95.6 \\
\hline 22 & Feb. 27 & $37+$ & 44 & 98.2 \\
\hline 23 & March 1 & $26+$ & 22 & 99.5 \\
\hline 24 & March 3 & 22 & 14 & 97.8 \\
\hline 25 & March 16 & $21-$ & 12 & 106.9 \\
\hline 26 & March 19 & $46-$ & 82 & 96.7 \\
\hline 27 & March 20 & $48-$ & 80 & 91.0 \\
\hline 28 & March 21 & $43-$ & 58 & 87.4 \\
\hline 29 & March 22 & 41 & 53 & 90.3 \\
\hline 30 & March 23 & $40+$ & 50 & 87.1 \\
\hline 31 & March 24 & 40 & 49 & 89.4 \\
\hline 32 & March 25 & $41-$ & 50 & 40.0 \\
\hline 33 & March 26 & $30+$ & 32 & 88.6 \\
\hline 34 & March 27 & 32 & 28 & 92.0 \\
\hline 35 & March 28 & 29 & 22 & 94.2 \\
\hline
\end{tabular}


TABLE 2. Dates and Times of Radar Observations Along With Geomagnetic and Solar Activity Parameters

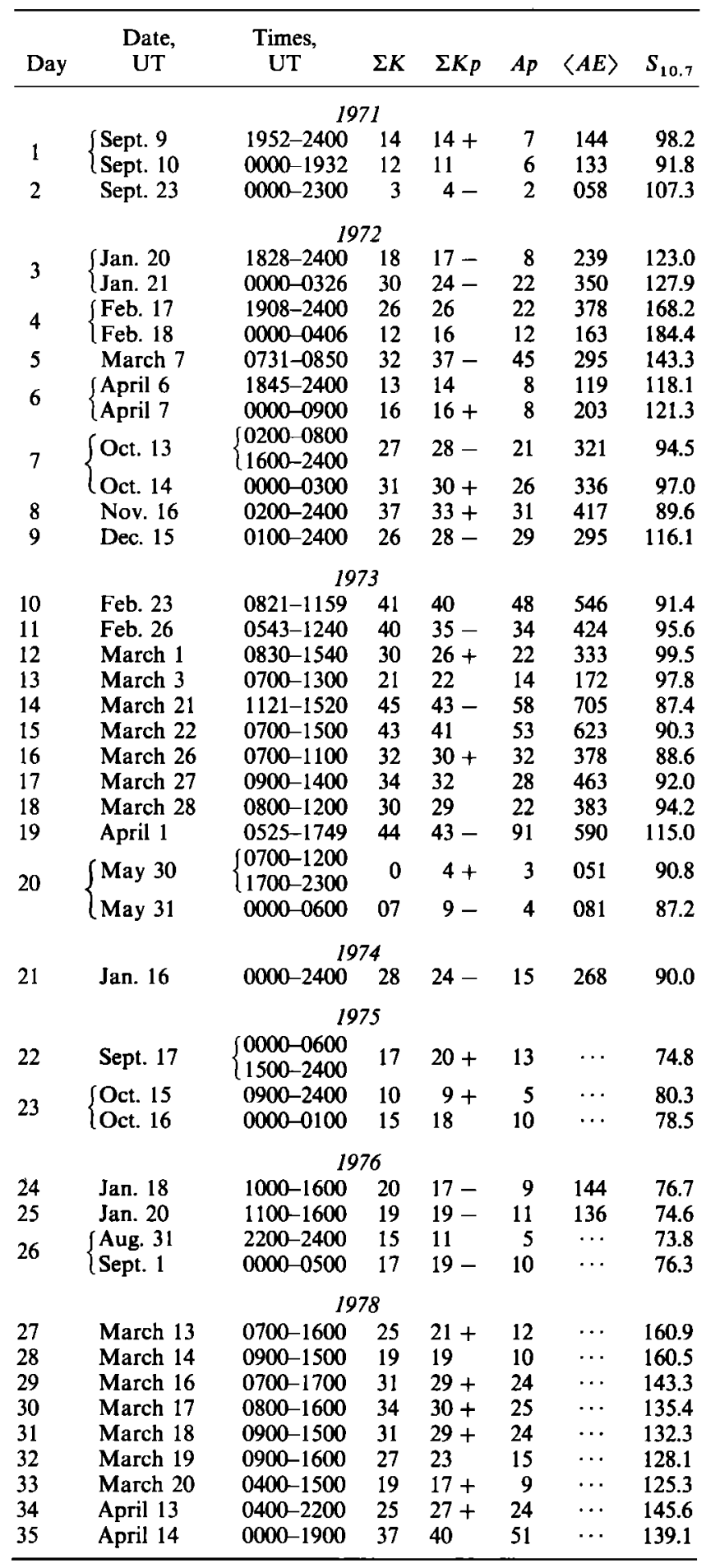

time, when the instrumental comparisons could be made, more measurements were acquired at the lower two altitudes, which were in keeping with the expected altitude of the FabryPerot measurements for auroral excitation. Hence, there is good agreement in altitude between the two data sets.

Figure 4 shows the distribution of radar values as a function of magnetic activity, $K p$. The activity was greater in 1973 compared to 1972 , and perhaps a little more active than for the radar measurements. However, the differences in the distributions of data as a function of magnetic activity are small.

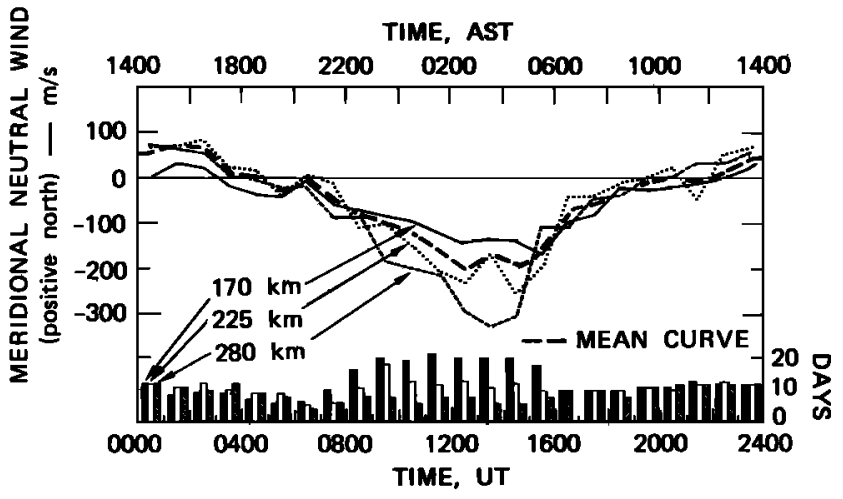

Fig. 3. Comparison of the mean meridional wind determinations for 170,225 , and $280 \mathrm{~km}$, and the overall mean wind. A histogram of the number of days on which the data existed for the three altitudes is included.

We have also divided the data set into two parts and compared the averages for indications of solar cycle effects. No detectable effects were found. Finally, as Table 2 shows, the distribution as a function of season is weighted largely by the equinoctial observations.

Thus, from the point of view of altitude, magnetic activity, solar cycle, and season, the good agreement among the averaged meridional winds in Figure 2 is significant.

A few cases of simultaneous observations of the meridional component of the thermospheric wind by the two instruments

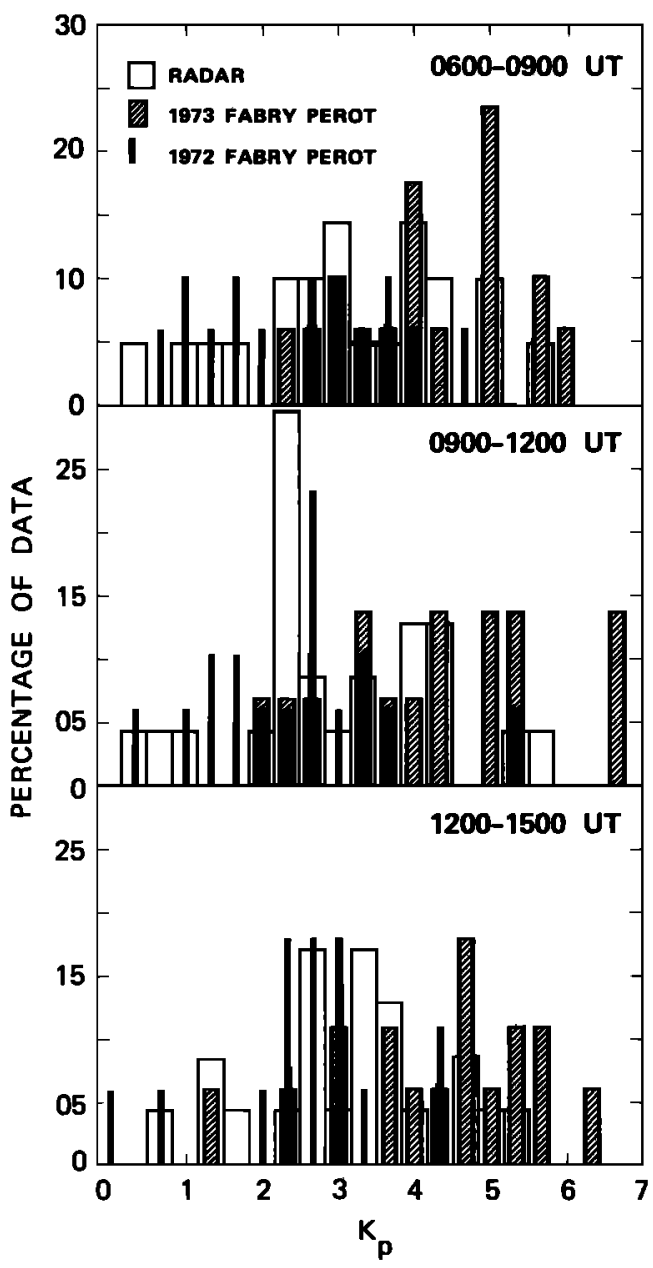

Fig. 4. Comparison of magnetic activity $K p$ for the radar and Fabry-Perot data. 


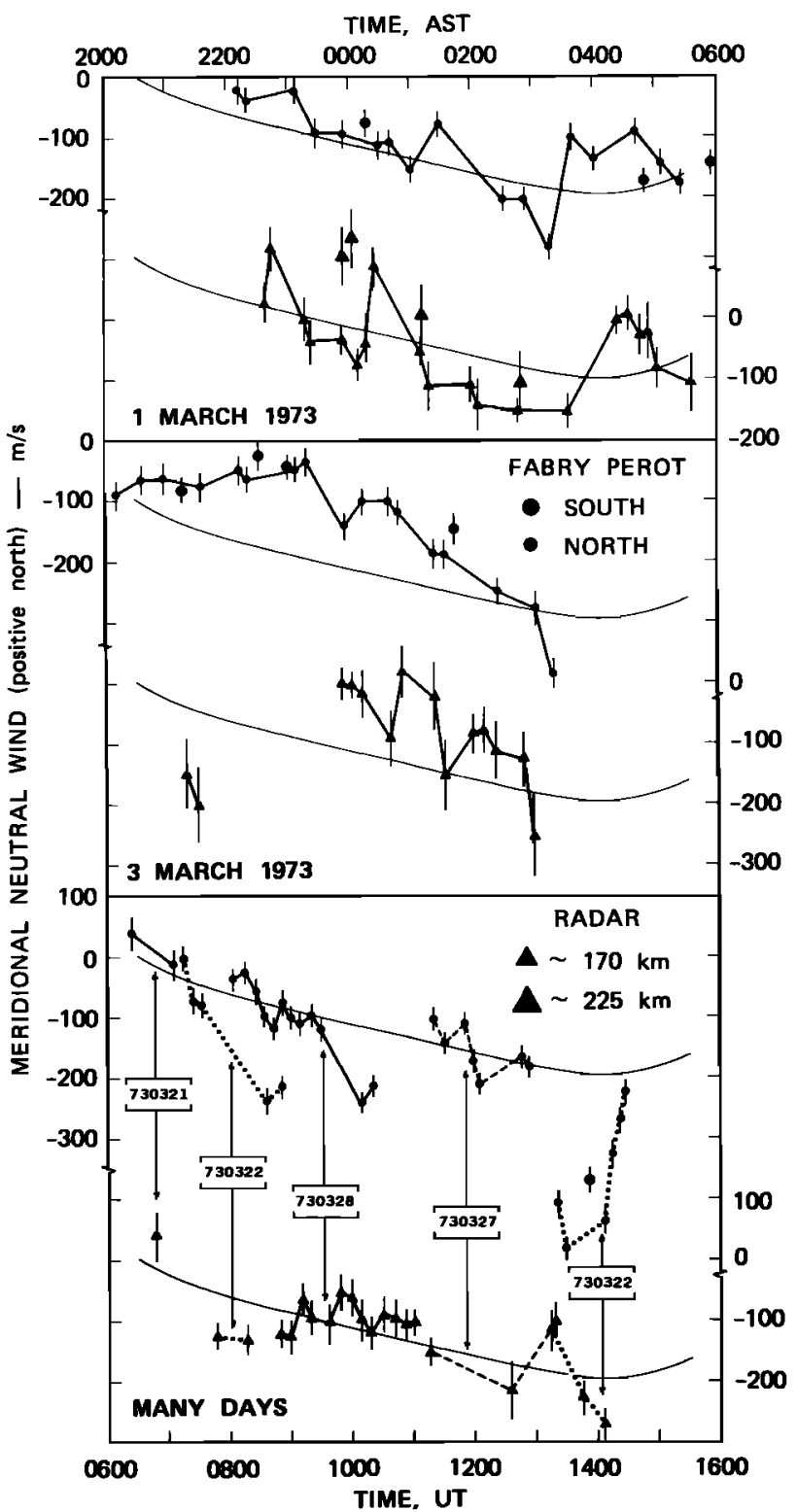

Fig. 5. Comparison of simultaneous determinations of the meridional wind with the radar and Fabry-Perot. A smooth average curve from the curves in Figure 2 is included with each set of measurements for reference.

were also examined. Only a few coincident observations exist; they are shown in Figure 5. Each panel has two sets of curves: the upper is for the Fabry-Perot, and the lower is for the radar. The smooth curves, which are an average of the radar and Fabry-Perot curves in Figure 2, serve as a reference for the two data sets. The agreement is good except for a few notable exceptions.

These are particularly interesting. We have examined the data for March 1, 1973, between 1000 and 1100 UT and between 0400 and 0500 UT because, on that day, the FabryPerot measured both the vertical and horizontal winds with good temporal resolution. We found that we cannot always assume that the vertical wind is much smaller than the horizontal component in the auroral region. This discovery does not change our determination of the reference for the FabryPerot because the combination of the argon reference and $6300-\AA$ zenith measurements allows us to identify these events and to remove them from the determination of the reference.
The radar is more sensitive to the vertical component than the Fabry-Perot when the latter is at an elevation angle of $30^{\circ}$, which accounts for the discrepancy noted between the two instruments. We believe that a gravity wave caused the enhanced vertical wind as described by Richmond [1978, 1979]. This result will be discussed at greater length in a later paper.

These winds have a characteristic time and altitude behavior that we have identified; we therefore removed these events from the averaged data. Indeed, before we removed these effects from the averaged data, we did not have the good agreement shown in Figure 2.

Thus, the radar/Fabry-Perot comparisons have proved very useful. They have enabled us to find occasions when the assumption of a purely horizontal wind is not valid. More generally, though, they show good agreement between the two methods. This agreement strengthens our confidence in both techniques and, in particular, enables us to combine measurements from the two techniques.

\section{$F$ Region Meridional Wind}

As we have shown in Figure 2, we have obtained a mean meridional wind for the $F$ region above Chatanika. This mean wind gives a reference for examining subsets of the total data set and specific days. As indicated in the introduction, one of our first interests is whether the meridional wind varies with magnetic activity. To examine this point, we divided the data set into the data with $K p$ values less than $3+$ and greater than $4-$. The results are presented in Figure 6 . In the bottom panel we show the results for high activity at the three altitudes for $K p \geq 4-$; in the next to bottom panel we show the results for low activity at the three altitudes for $K p \leq 3+$. There are differences between these curves: to make the differences more obvious, we have averaged together the three altitudes and presented the results in the second panel. In the afternoon and evening, between 1200 and 2300 local time (2200 and 0900 UT), the difference is not significant. But during the night and morning from 2300 to 1200 AST, the difference is significant. The largest increase occurs to the south during the night between 0000 and 0600 AST and is of the order of $100 \mathrm{~m} / \mathrm{s}$. To further examine these differences, we have only looked at the lowest altitude in the top panel, which shows the average

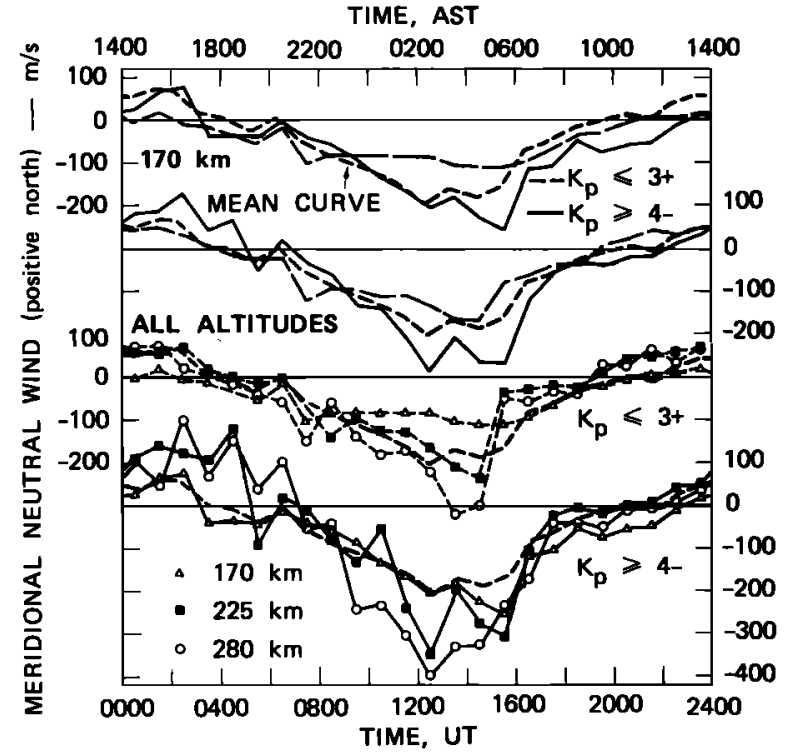

Fig. 6. Variation of the mean meridional wind with magnetic activity. 
meridional wind for $K p \leq 3+$ and $K p \geq 4-$ for $170 \mathrm{~km}$, with the same results. Thus, under all conditions in this time period there is a net velocity to the south. Moreover, there is an increase in that velocity during periods of magnetic activity in agreement with the large meridional winds during magnetic storms observed by Hays and Roble [1971b].

The next question is whether there is a discernable seasonal variation. In our data sample we do not have enough cases of winter and summer measurements to establish a seasonal pattern. However, we can divide the data according to season and see if the data that we do have are consistent with the theoretical predictions. In Figure 7 we show the results. As indicated in the previous section, most of the data are from the equinoxes. There is only one summer day, but on that day the wind is approximately $100 \mathrm{~m} / \mathrm{s}$ stronger to the south than on the other days. This effect is not likely to be caused by magnetic activity because this is the quietest day in the whole data set. Thus, this shift is consistent with the seasonal predictions that arise from a summer-winter pressure gradient caused by greater upper atmospheric temperatures in the summer hemisphere than in the winter hemisphere [Dickinson et al., 1981].

Slightly more data are available from the winter period. During the day, the data are very similar to the mean data, but during the night, the southward velocities are reduced approximately $100 \mathrm{~m} / \mathrm{s}$. Again, this is the same direction as predicted by theory.

\section{Comparison With Theoretical Models}

In this section we compare our observations to model calculations in order to gain an understanding of the physical processes affecting the measurements and to assess the status of the models. First, we compare with 3 three-dimensional models, Figures $8 a-8 c$. The model calculations are for $F$ region heights, between 240 and $300 \mathrm{~km}$; for moderate to active solar cycle conditions, $F_{10.7}$ between 140 and 165 $\times 10^{-22} \mathrm{~W} \mathrm{~m}^{-2} \mathrm{~Hz}^{-1}$, and for equinox. The curves presented assume coincident geographic and geomagnetic poles. In each part of Figure 8 a curve is presented for the effect of solar input alone and one or two curves for the solar input combined with magnetospheric convection. For comparison the two curves of observed meridional wind for low and high magnetic activity from the second panel in Figure 6 are included.

In general, there is good agreement between observation and theory. The two more recent and more complex models

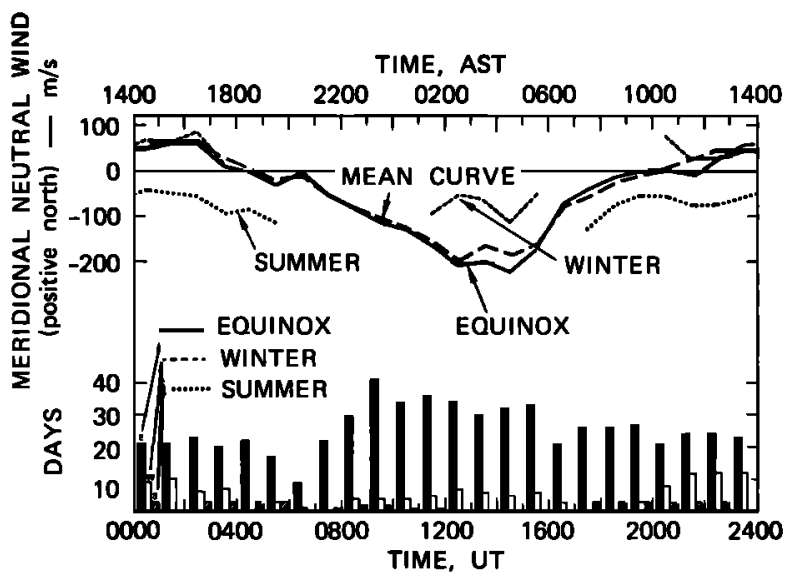

Fig. 7. Variation of the mean meridional wind with season. A histogram of the number of days from each season is included.

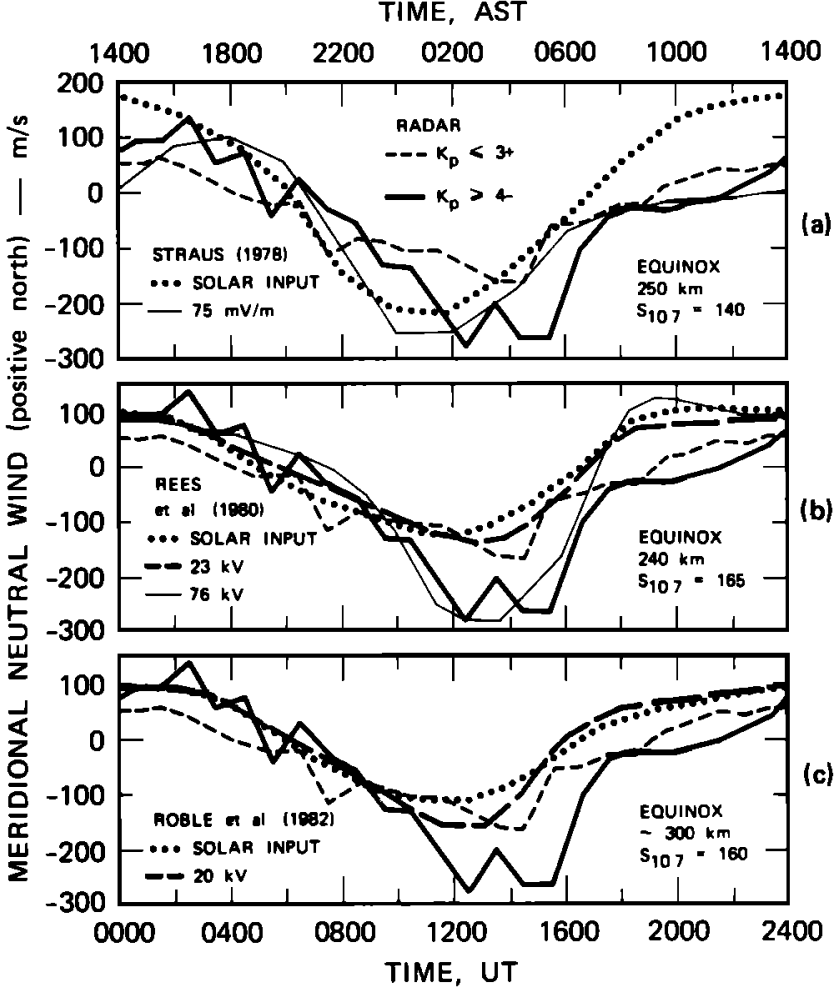

Fig. 8. Comparisons of theoretical meridional winds with radar observations. The radar observations are for high and low magnetic activity from Figure 6.

come closer to matching the observations than the earlier model. In particular, the daytime and nighttime extremes for solar input alone and solar input plus moderate convection are reduced, thereby coming closer to the lower activity observations. The solar activity plus high convection curve of Rees et al. [1980] matches the early morning higher activity observations much better than the analogous curve of Straus [1978]. Principally, it occurs later, but the southward wind also increases by an amount more similar to what is observed. Since this equatorward feature is believed to result from ion drag [Rees et al., 1980; Roble et al., 1982], the different behavior may reflect differences in the ion convection pattern or the $F$ region ion concentration. In the evening sector, all three models indicate that with increasing geomagnetic activity the meridional wind is more poleward than otherwise, presumably due to greater ion drag, which has a northward as well as a westward component. The limited high activity data are also poleward of the low activity data in this period.

However, there are some significant differences in behavior. All the theoretical calculations reach their equatorward maximum and turn poleward one to two hours ahead of the observations. It is not obvious whether this discrepancy arises because of coincident geographic and geomagnetic poles in the calculations, or whether there is deeper physical significance. We note that at the equinoxes, magnetic midnight is 1.5 hours after local midnight. Although such a shift of the calculated values to later times would improve the morning comparison, it would damage the evening comparison. Thus, there is a hint that the early morning discrepancy or phase problem may be indicative of something more interesting. Perhaps an additional heat source such as soft particle precipitation is needed in the polar cap, as proposed by Rees et al. [1980]. Certainly, in the late morning and noon sectors, the observed wind is 50 to $100 \mathrm{~m} / \mathrm{s}$ equatorward of the calculated wind. 


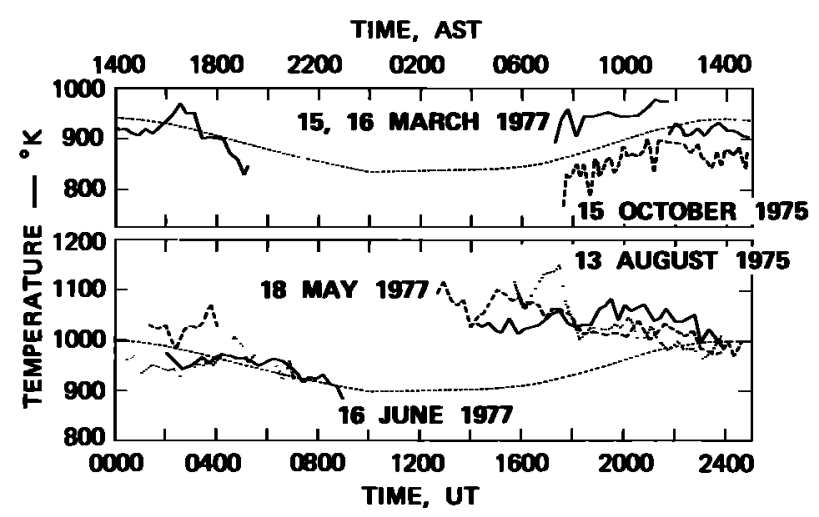

Fig. 9. Two different exospheric temperature behaviors compared to the Jacchia model behavior. The exospheric temperature was found only when the electric fields were practically zero.

During the late morning, under active conditions it is even more equatorward. Since Chatanika is south of the auroral oval at these times, it is possible that this discrepancy arises because of Joule heating as described by Straus [1978] for his high activity curve.

Second, we refer the reader to the paper by Hays et al. [1979] where an attempt is made to fit the 1972 Fabry-Perot data, including the meridional component that we showed in Figure 2. In addition to the neutral winds, they use the average ion velocities from the radar obtained during February 1972. Initially, Hays et al. used the mass spectrometer/incoherent scatter (MSIS) model to calculate the winds; then they used the MSIS model combined with the averaged ion velocities. In neither case were the calculations particularly close to the observations. When a nighttime heat source was added, agreement was achieved for a neutral temperature distribution that increased during the night in contrast to the decrease shown by all of the models. This type of temperature distribution has on occasion been seen at Chatanika. In Figure 9, we show the exospheric temperature variation obtained for two sets of days at Chatanika from the radar data. In the top set, the variation follows that of the Jacchia 1971 model (which behaves similarly to the MSIS model) whereas in the other set, the temperature is substantially greater in the early morning than in the late evening and in the model. Thus, it appears that considerable heating can occur poleward of Chatanika during the night and early morning. It may be a poleward extension of the Joule heating described by Baron and Wand [1983] and it might contribute

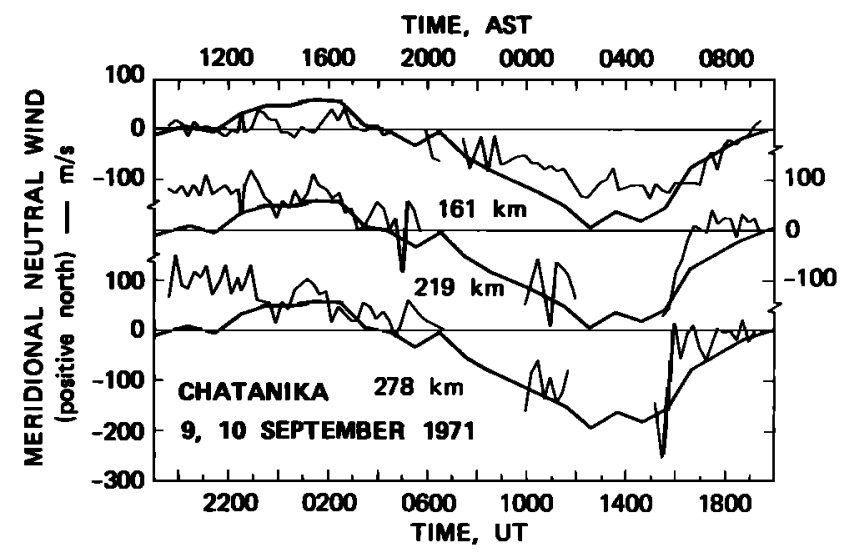

Fig. 10. Meridional winds for September 9 to 10,1971 , a very quiet period magnetically.

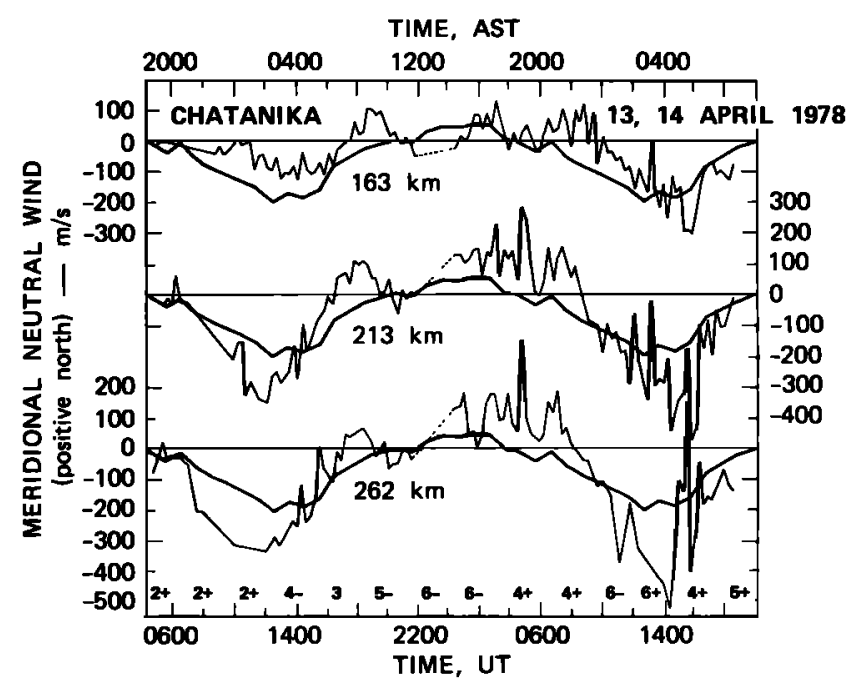

Fig. 11. Meridional winds for April 13 to 14,1978 . The $K p$ values are given at the bottom of the figure.

to the morning discrepancy just described in relation to Figure 8.

Thus, from this comparison of observation with theory, it appears that there is a need for both a daytime and a nighttime heat source that would be situated poleward of the auroral region so as to increase the equatorward meridional wind.

\section{INDIVIDUAL CASES}

Before we summarize our discussion on the meridional wind, a look at the data from several individual experiments may be instructive. In Figure 10, we show the wind from a magnetically very quiet day. In Figure 11, we show the wind from a 36-hour period. During the first 12 hours, the geomagnetic activity is low; during the last 24 hours, it is high. In Figure 12, we show the wind for a very active 12-hour period. In all three figures, the mean curve from Figure 2 is included for comparison. The data points were determined at 10-min intervals and were omitted if the uncertainty exceeded $50 \mathrm{~m} / \mathrm{s}$. The large spikes in the data, such as at 1530 UT on April 14, 1978, and at 1510 and 1640 UT on April 1, 1973, are examples of contamination of the derived wind calculations by the gravity waves referred to earlier.

On the first day of Figure 10, the data are close to the mean curve, but tend to show winds that are not as strong to the south. On the last day of Figure 12, the nighttime winds, even at the lowest altitude, are considerably stronger to the south than the mean. Between 1700 and 1900 UT in the morning on

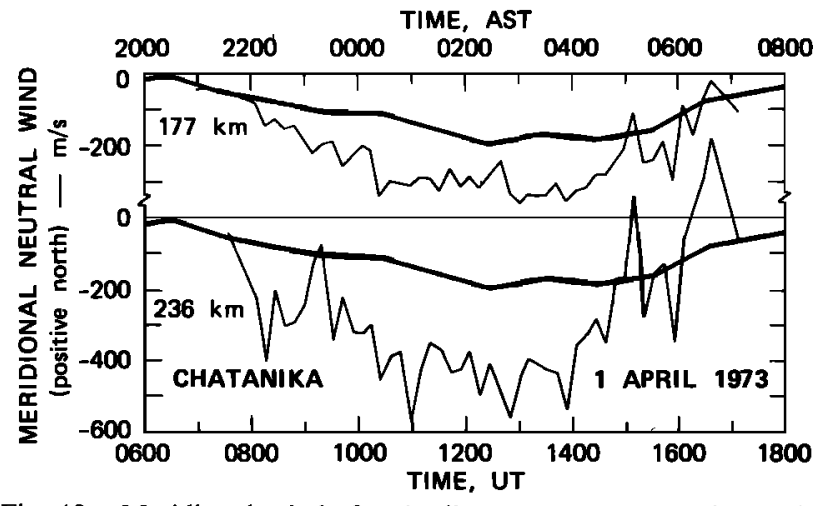

Fig. 12. Meridional winds for April 1, 1973, a very active period magnetically. 
April 14, 1978 (Figure 11), the winds are considerably stronger to the south than on the preceding day, as we might expect because of the greater magnetic activity. However, between 0400 and 0800 UT in the early evening on April 14, the winds are stronger to the north than on the preceding day despite the greater magnetic activity. Thus, we see considerable dayto-day variability in addition to the effects of magnetic activity.

An altitude gradient seems to be present in these meridional winds, particularly at night, just as in the averaged data in Figure 3. During the night, the southward wind increases significantly with altitude. A small phase shift may be present with the lowest altitude responding slightly later. During the day, from roughly 1800 to $0600 \mathrm{UT}$, the wind at the upper two altitudes often appears stronger to the north than at the lowest altitude.

\section{CoNCLuSIONS}

This is the first of several papers on thermospheric wind measurements in the auroral region that combine incoherent scatter radar and Fabry-Perot measurements. The measurement and analysis procedures are presented for both instruments. The procedure for the Chatanika radar is simpler than for Millstone Hill and Arecibo because the measurements were made with the radar directed toward the magnetic zenith. The magnitude of the corrections for ion-neutral diffusion has been kept small by using data primarily from the vicinity of $200 \mathrm{~km}$. However, to perform this correction it is necessary to make certain reasonable assumptions about the ion composition, the neutral temperature profile, and the electron-to-ion temperature ratio, as well as to assume that the neutral motion was horizontal. The Fabry-Perot analysis procedure was standard, but we assume that the $O\left({ }^{1} D\right)$ atoms excited by energetic electrons that penetrate to far lower altitudes are quenched so that the centroid height of the $6300-\AA$ volume emission profile remains constant regardless of the spectral hardness of the precipitating flux. In addition, in the analysis process we assume that the population of emitting $O\left({ }^{1} D\right)$ atoms was thermalized.

Therefore the first step was a comparison between the meridional winds determined by the two techniques. This comparison showed occasions with significant vertical winds. When these events were eliminated, good agreement was obtained between the two techniques, thereby strengthening our confidence in the two meridional wind determinations. The next step was an examination of one-hour averages of radar data obtained over a seven-year period for general properties of the meridional wind. Most of the data were from the equinoxes. Averaged over 24 hours, there was a net equatorward flow. Under magnetically active conditions, $K p \geq 4-$, the wind to the south was significantly stronger during the night and little changed during the day. The maximum equatorward wind may shift later with increased magnetic activity. While there were not enough days to draw any conclusion about seasonal variations, the observed variations are consistent with stronger flow in the summer than the winter hemisphere.

The third step consisted of comparisons to theory. During the daytime the northward wind was smaller than predicted. A possible explanation is a daytime heat source poleward of Chatanika, e.g., the cusp. At night, Hays et al. [1979] needed to invoke heating such that $T_{\infty}$ increased during the night. Such behavior has indeed been seen at Chatanika. This heating would most likely occur on the poleward side of the auroral oval or in the polar cap. If it occurred equatorward of these positions, for instance in the electrojet, then on active days it would occur south of Chatanika and act to reduce rather than enhance the wind. Regions of polar cap heating have been recently observed by Dynamics Explorer B [Hays et al., 1984]. The source of this heating remains to be identified.

The fourth step consisted of presenting meridional winds with $10-\mathrm{min}$ resolution instead of one-hour averages. These data showed considerable variation from the mean behavior including periods of vertical motion, variations occurring on time scales short compared with an hour, day-to-day variations, and the largest equatorward wind in the data set.

The new location of the radar in Sondre Stromfjord at a magnetic latitude corresponding to the cusp together with the imaging Fabry-Perot interferometer recently installed at Sondre Stromfjord will provide an opportunity to continue the intercomparison of results obtained by the two instruments as described in this paper.

\section{APPENDIX}

\section{Analysis of the Incoherent-Scatter Data for the Meridional} Neutral Wind at Thermospheric Heights

Analysis of Chatanika data is simplified because the data were acquired with the radar pointing toward magnetic zenith. At altitudes appropriate for comparison with the Fabry-Perot and where we have the best ratios of signal to noise, the effects of a mixture of atomic and molecular ions must be considered. We have also simplified the analysis on the basis of several assumptions that need to be justified. Accordingly, we include a full derivation of the analysis procedure.

Above about $150 \mathrm{~km}$, the ion gyrofrequency, $\Omega_{i}$, is much greater than the ion-neutral collision frequency, $v_{i}$, with the effect that the steady state equations of motion for the electrons and ions become

$$
\mathbf{E}_{p}+\mathbf{V}_{p} \times \mathbf{B}=0
$$

for ions and electrons moving perpendicular to $\mathbf{B}$, and

$$
n_{i} m_{i} v_{i}\left(U_{11}-V_{11}\right)-\sin I\left(\frac{\partial p_{i}}{\partial h}+n_{i} m_{i} g\right)+n_{i} e \mathbf{E}_{11}=0
$$

for ions and

$$
n_{\mathrm{e}} m_{e} v_{e}\left(U_{11}-V_{e 11}\right)-\sin I\left(\frac{\partial p_{e}}{\partial h}+n_{e} m_{e} g\right)-n_{e} e \mathbf{E}_{11}=0
$$

for electrons moving parallel to $\mathbf{B}$.

The various parameters for these equations are defined as follows:

$\mathbf{E}_{\boldsymbol{p}}$ applied electric field perpendicular to $\mathbf{B}$;

$\mathbf{E}_{11}$ polarization electrostatic field;

B magnetic field;

I magnetic field inclination or dip angle (76.5 at Chatanika);

$U_{11}$ neutral wind parallel to the magnetic field and positive away from the earth;

$\mathrm{V}$ velocity of ions of species $i$, equal to $\mathrm{V}_{p}+V_{11}$; $V_{11}$ positive away from the earth;

$\mathbf{V}_{e}$ electron velocity, equal to $\mathbf{V}_{e p}+V_{e 11}$;

$p_{1}$ partial pressure of ions of species $i$, equal to $n_{i} k T_{i}$; 
$p_{e} \quad$ partial pressure of the electrons, equal to $n_{e} k T_{e}$;

$n_{i}, m_{1}, T_{i}$ concentration, mass, and temperature of ions of species $i$;

$n_{e}, m_{e}, T_{e}$ concentration, mass, and temperature of the electrons;

$v_{i}$ total ion-neutral collision frequency for ions of species $i$, equal to $\sum_{n} v_{i n}$

$v_{e}$ total electron-neutral collision frequency, equal to $\sum_{n} v_{e n}$.

Examination of these equations shows that the neutral wind does not affect the ion velocity perpendicular to the magnetic field, but does affect the ion motion parallel to the magnetic field. When we solve (A2) and (A3) for the polarization electric field and drop terms of the order of $m_{e} / m_{l}$, we obtain

$$
\begin{aligned}
V_{11}=U_{11}-\frac{k T_{i}}{m_{1} v_{t}} \sin I\left\{\frac{1}{T_{t}} \frac{\partial\left(T_{i}+T_{e}\right)}{\partial h}\right. & +\frac{1}{n_{i}} \frac{\partial n_{i}}{\partial h} \\
& \left.+\frac{T_{e}}{T_{i}} \frac{1}{n_{e}} \frac{\partial n_{e}}{\partial h}+\frac{m_{i} g}{k T_{i}}\right\}
\end{aligned}
$$

For a major ion, such that $n_{i} \simeq n_{e}$, this equation becomes

$$
\begin{gathered}
V_{11}=U_{11}-D \sin I\left\{\frac{1}{T_{p}} \frac{\partial T_{p}}{\partial h}+\frac{1}{n_{e}} \frac{\partial n_{e}}{\partial h}+\frac{m_{i} g}{2 k T_{p}}\right\} \\
V_{11}=U_{11}-V_{D} \sin I
\end{gathered}
$$

where $T_{p}=\left(T_{t}+T_{e}\right) / 2$ is the plasma temperature, $D=2 k T_{p} /$ $m_{i} v_{t}$ is the ion-neutral diffusion coefficient, and $V_{D}$ is the ionneutral diffusion velocity for ions of species $i$.

Physically, (A6) states that the motion of the major ion species parallel to the magnetic field is controlled by collisions with neutrals, pressure gradients arising from gradients in temperature, concentration, and gravity. Its application above $250 \mathrm{~km}$ is straightforward because $\mathrm{O}^{+}$is usually the dominant ion species [Kelly and Wickwar, 1981] and $m_{1}$ and $v_{i}$ can be replaced by $m_{\mathbf{O}}+$ and $v_{\mathbf{O}+}$. Similarly, the ion velocity measured by the radar is that of $\mathrm{O}^{+}$.

However, between 150 and $250 \mathrm{~km}$, the situation is not as clear because there is a mixture of mostly $\mathrm{O}_{2}{ }^{+}, \mathrm{NO}^{+}$, and $\mathrm{O}^{+}$ ions. The question arises whether these ions have different diffusion velocities and how they affect the radar measurements. First, the $\mathrm{O}_{2}{ }^{+}$ions can be discounted in favor of the $\mathrm{NO}^{+}$ions. Usually, the $\mathrm{NO}^{+}$concentration is far greater than the $\mathrm{O}_{2}{ }^{+}$concentration [Swider and Narcisi, 1977]; additionally, the normalized gradients [Swider and Narcisi, 1977], masses, and ion-neutral collision frequencies [Schunk and Walker, 1973] are nearly the same. Second, we must examine the difference in ion-diffusion velocities for $\mathrm{NO}^{+}$and $\mathrm{O}^{+}$. Let us define

$$
q=\frac{\left[\mathrm{O}^{+}\right]}{n_{e}} \quad p=\frac{\left[\mathrm{NO}^{+}\right]}{n_{e}} \quad p+q=1
$$

Equation (A4) then becomes

$$
\begin{aligned}
V_{11}=U_{11}-D_{\mathrm{O}+} \sin I\left\{\frac{1}{T_{p}} \frac{\partial T_{p}}{\partial h}+\frac{1}{n_{e}} \frac{\partial n_{e}}{\partial h}\right. & +\frac{m_{\mathrm{O}+} g}{2 k T_{p}} \\
& \left.+\frac{T_{i}}{2 T_{p}} \frac{1}{q} \frac{\partial q}{\partial h}\right\}
\end{aligned}
$$

for $\mathrm{O}^{+}$and

$$
\begin{array}{r}
V_{11}=U_{11}-D_{\mathrm{NO}}+\sin I\left\{\frac{1}{T_{p}} \frac{\partial T_{p}}{\partial h}+\frac{1}{n_{e}} \frac{\partial n_{e}}{\partial h}+\frac{m_{\mathrm{NO}+g}}{2 k T_{p}}\right. \\
\left.-\frac{T_{i}}{2 T_{p}(1-q)} \frac{\partial q}{\partial h}\right\}
\end{array}
$$

for $\mathrm{NO}^{+}$. For reasonable composition gradients, the difference in ion diffusion velocities is less than $5 \mathrm{~m} / \mathrm{s}$. Because this difference is small, we make the simplifying assumption that the one ion velocity found from the Doppler shift of the radar signal is

$$
V_{11}=U_{11}-\left\langle V_{D}\right\rangle \sin I
$$

where

$$
\begin{gathered}
\left\langle V_{D}\right\rangle=q V_{\mathrm{O}^{+}}+p V_{\mathrm{NO}^{+}} \\
\left\langle V_{D}\right\rangle=\frac{2 k T_{p}}{\left\langle m_{i} v_{i}\right\rangle}\left\{\frac{1}{T_{p}} \frac{\partial T_{p}}{\partial h}+\frac{1}{n_{e}} \frac{\partial n_{e}}{\partial h}\right\}+\frac{g\left\langle m_{i}\right\rangle}{\left\langle m_{i} v_{i}\right\rangle}
\end{gathered}
$$

If the difference in diffusion velocities were large, we would have to be more careful in considering the radar signal because it is not a linear superposition of the signals scattered from the two ion species.

In the analysis program, we further simplify by replacing $\left\langle m_{i} v_{i}\right\rangle$ by $\left\langle m_{i}\right\rangle\left\langle v_{l}\right\rangle$. This simplification has no significant effect because the ion-neutral diffusion velocity is itself very small compared to the uncertainty in $V_{11}$ in this altitude region where there is a mixture of ions.

If we can assume that the neutral motion is horizontal, then

$$
U_{11}=-U_{\text {merid }} \cos I
$$

and the horizontal neutral wind in the magnetic meridian is given by

$$
U_{\text {merid }}=-\frac{V_{11}}{\cos I}-\frac{2 k T_{p} \tan I}{\left\langle m_{i} v_{i}\right\rangle}\left\{\frac{1}{T_{p}} \frac{\partial T_{p}}{\partial h}+\frac{1}{n_{e}} \frac{\partial n_{e}}{\partial h}+\frac{\left\langle m_{i}\right\rangle g}{2 k T_{p}}\right\}
$$

The sign convention adopted is that $U_{\text {merid }}$ is positive to the north.

In (A14), $V_{11}$ and $\left(1 / n_{e}\right)\left(\partial n_{e} / \partial h\right)$ are obtained from the radar measurements. The other terms involving the ion composition, $\left\langle m_{i}\right\rangle,\left\langle m_{i} v_{i}\right\rangle,\left\langle v_{1}\right\rangle, T_{p}$, and $\left(1 / T_{p}\right)\left(\partial T_{p} / \partial h\right)$, are obtained from models. These models have been chosen to approximate much of the radar data. The neutral atmosphere used to calculate the $v_{i}$ and the temperatures is the $1000-\mathrm{K}$ atmosphere of Banks and Kockarts [1973], with the assumption that

$$
T_{e}=2 T_{i}=2 T_{n}
$$

The ion composition is considered $75 \% \mathrm{NO}^{+}$and $25 \% \mathrm{O}_{2}{ }^{+}$ below $150 \mathrm{~km}$, entirely $\mathrm{O}^{+}$above $250 \mathrm{~km}$, and a linearly varying mixture in between the two altitudes.

The use of model quantities to calculate parts of the diffusion velocity in (A14) has a greater impact on the uncertainty than the assumption previously introduced to obtain (A12). Yet, detailed calculations of the ion-neutral diffusion velocity show that the diffusion correction is negligible below $225 \mathrm{~km}$ when compared with the ion velocity measurement uncertainty. The values assumed for the temperatures and for the collision frequencies become increasingly important at higher altitudes. It may be possible later to use the radar measurements of temperatures to improve the diffusion calculation and thereby to deduce meridional winds at higher altitudes. 
Alternatively, if chemical releases or satellite measurements showed that no gradient in $U_{\text {merid }}$ existed above some altitude, then we could find the variation of $v_{\mathrm{O}^{+}}$(or of atomic oxygen density) with altitude.

\section{MAO Fabry-Perot Observations:}

Techniques and Analysis

The instrumental technique was improved in 1973 with a modification of the pressure scanning equipment that replaced the needle valve connected to a gas bottle with a pressurized cylinder fitted with a motorized piston. The application of this pressure stepper generated a sequential scan across the emission profile that was nearly linear in density; for each step position of the piston the pressure was measured simultaneously with the counted pulses with a precision of $0.15 \%$. The design of a similarly constructed pressure stepper has been described by Burnside et al. [1981] and Meriwether et al. [1983].

This innovation reduced by 1 order of magnitude the thermal effects generated by the venting phase of the open flow pressure scanning technique in 1972. A study of the thermal characteristics of the closed scan cycle with the results shown in Figure A1 indicated that the observed etalon density behavior for a scan in the direction of increasing pressure was a virtual mirror image of the response in the reverse cycle. Therefore, we averaged the two scans together for both pressures and count rates. The etalon temperature was monitored throughout these measurements and these values were used to convert the pressure readings to densities before data analysis.

The algorithm of the data analysis for the 1972 observations was described by Hays and Roble [1971a]. For this method it is necessary to scan over a full free spectral range. Measurements showed that the value of the free spectral range remained constant to $0.5 \%$ or less. Hence, the sampling of the
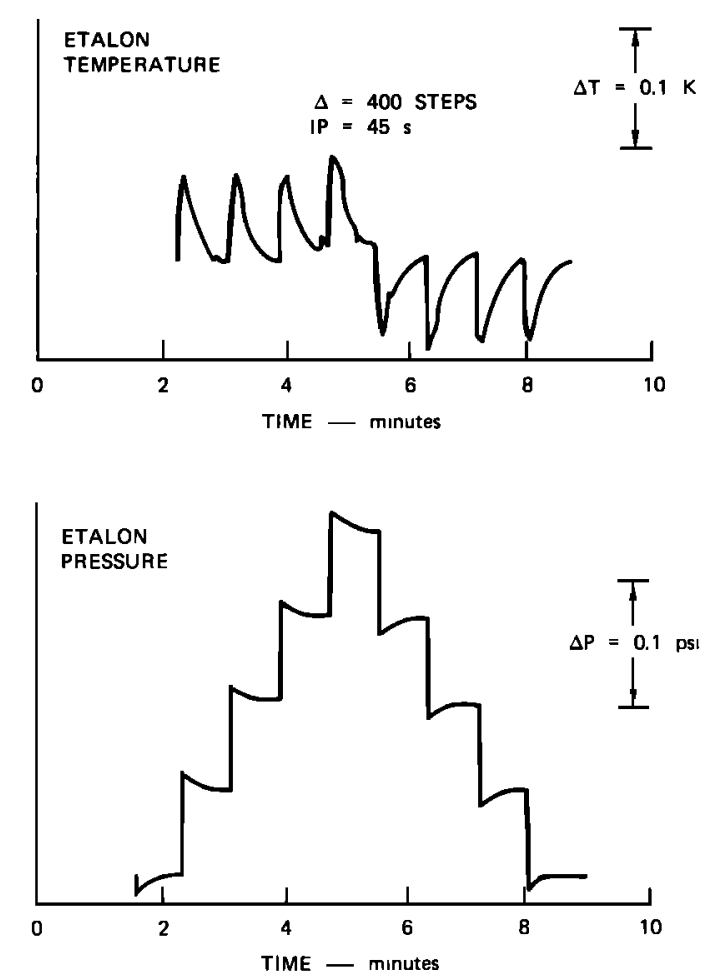

Fig. A1. Etalon temperature and pressure for a Fabry-Perot etalon wavelength scan cycle. emission profile could be made more efficient if the background region composing about $50 \%$ of the free spectral range for the $1-\mathrm{cm}$ spacers used was omitted.

Accordingly, seven spectral positions were chosen for the sampling of the $6300-\AA$ emission profile over $49 \%$ of the free spectral range. In the data analysis described by Hernandez [1982], where Fourier transforms of the observations are used to process the data, a total of 14 positions in one free spectral range are needed to avoid errors in the temperature determination resulting from the aliasing caused by undersampling [Zipoy, 1979], and a total of eight positions are required to avoid a similar error in the Doppler position determination. Zipoy [1979] has noted that the restriction of the emission profile scan to one full free spectral range may be relaxed without introduction of sidebands into the deconvoluted profile if a choice of spacing between adjacent points of $\frac{1}{2}$ the full width at half maximum of the Fabry-Perot fringe were used.

The analysis of the 1973 observations [Nagy et al., 1974] applied the method of nonlinear least squares in which the fitting function was derived from the explicit evaluation of the convolution integral involving the source emission profile (assumed to be Gaussian) with the instrumental function described by a truncated complete Fourier series with coefficients derived from a calibration with a cooled $\mathrm{Hg}_{198}$ lamp. This function relates the four unknowns of the Doppler profile, namely, the background continuum brightness, $B_{\lambda}$, the integrated column brightness, $\boldsymbol{R}_{\lambda}$, the center of gravity position, $\lambda_{c}$, and the Doppler width, $\delta \lambda_{T}$, to the observed count rate, $Y_{i}$, at the wavelength corresponding to the pressure, $p_{i}$. The mathematical expression for it is

$$
\begin{aligned}
Y_{i} & =A+B \sum_{m}\left\{\alpha_{m}{ }^{*} \cos \left[\frac{2 \pi m}{\Delta \lambda}\left(\lambda-\lambda_{c}\right)\right]\right. \\
& \left.+\beta_{m}{ }^{*} \sin \left[\frac{2 \pi m}{\Delta \lambda}\left(\lambda-\lambda_{c}\right)\right]\right\} \exp \left(-\pi^{2} m^{2} \delta \lambda_{T}{ }^{2} / \Delta \lambda^{2}\right)
\end{aligned}
$$

where the factors $\alpha_{m}{ }^{*}$ and $\beta_{m}{ }^{*}$ are the Fourier coefficients determined with the mercury lamp calibration but normalized to unity area. The constants $A$ and $B$ relate to the background continuum brightness and the integrated column brightness. Successive inversions of the normal equations in the method of least squares determine the best set of values for the four unknown quantities, $A, B, \lambda_{T}$, and $\lambda_{c}$ that fits this fitting function to an experimental set of profile measurements, $Y_{i}$. An extension of this technique was used for the analysis of the DE FPI observations [Hays et al., 1981; Killeen and Hays, 1984].

There were two reasons for choosing a total of seven samples across the $49 \%$ fraction of the free spectral range used. The first was the increased sampling rate of the spectral profile peak improving the ratio of signal to noise by about $40 \%$. The other was the reduction in the amount of data processing required while providing the information needed to deduce the properties of the Doppler profile. The price we pay lies in the inherent assumption that the source spectral profile is Gaussian.

Acknowledgments. We would like to thank the staff members at SRI International and the University of Michigan who made this research possible. We also extend our appreciation to the Geophysical Institute at the University of Alaska for its hospitality in making feasible the optical observations. Through the years, the observations have been supported by grants from the National Science Foundation. The Chatanika radar was operated under grants from the Na- 
tional Science Foundation and contracts from the Defense Nuclear Agency. The SRI support for the analysis was provided by AFOSR contracts F49620-78-C-0018 and F49620-83-K-0005, and by NSF Cooperative Agreement ATM8121671. The University of Michigan support for the completion of this paper was provided by NSF ATM8202440.

The Editor thanks H. C. Carlson and another referee for their assistance in evaluating this paper.

\section{REFERENCES}

Abreu, V. J., G. A. Schmitt, P. B. Hays, J. W. Meriwether, C. A. Tepley, and L. L. Cogger, Atmospheric scattering effects on ground-based measurements of thermospheric winds, Planet. Space Sci., 34, 1-10, 1983.

Armstrong, E. B., Doppler shifts in the wavelength of the OI 6300 line in the night airglow, Planet. Space Sci., 17, 957-974, 1969.

Banks, P. M., and G Kockarts, Aeronomy, Academic, New York, 1973.

Baron, M. J., and R. H. Wand, $F$ region ion temperature enhancements resulting from Joule heating, J. Geophys. Res., 88, 4114-4118, 1983.

Burnside, R. G., J. W. Meriwether, Jr., and J. C. G. Walker, Optical observations of thermospheric dynamics at Arecibo, J. Geophys. Res., 86, 5532-5540, 1981.

Cogger, L. L., J. C. G. Walker, J. W. Meriwether, Jr., and R. G. Burnside, $F$ region alrglow: Are ground-based observations consistent with recent satellite results?, J. Geophys. Res., 85, 3013-3020, 1980.

Dickinson, R. E., C. P. Lagos, and R. E. Newell, Dynamics of the neutral gas in the thermosphere for small Rossby number motions, J. Geophys. Res., 73, 4299-4313, 1968.

Dickinson, R. E., E. C. Ridley, and R. G. Roble, A three-dimensional general circulation model of the thermosphere, J. Geophys. Res., 86, $1499-1512,1981$.

Fuller-Rowell, T. J., and D. Rees, A three-dimensional, timedependent simulation of the global dynamical response of the thermosphere to a geomagnetic substorm, J. Atmos. Terr. Phys., 43, 701-721, 1981.

Geisler, J. E., A numerical study of the wind system in the middle thermosphere, J. Atmos. Terr. Phys., 29, 1469, 1967.

Hays, P. B., and R. G. Roble, A technique for recovering Doppler line profiles from Fabry-Perot interferometer fringes of very low intensity, Appl. Opt., 10, 193, 1971a.

Hays, P. B., and R. G. Roble, Direct observations of thermospheric winds during a geomagnetic storm, J. Geophys. Res., 76, 5316-5321, $1971 b$.

Hays, P. B., J. W. Meriwether, Jr., and R. G. Roble, Nighttime thermospheric winds at high latitudes, J. Geophys. Res., 84, 1905-1913, 1979.

Hays, P. B., T. L. Killeen, and B. C. Kennedy, The Fabry-Perot interferometer on Dynamics Explorer, Space Sci. Instrum., 5, 395$416,1981$.

Hays, P. B., T. L. Killeen, N. W. Spencer, L. E. Wharton, R. G. Roble, B. A. Emery, T. J. Fuller-Rowell, D. Rees, L. A. Frank, and J. D. Craven, Observations of the dynamics of the polar thermosphere, J. Geophys. Res., 89, 5597-5612, 1984.

Heppner, J. P., and M. L. Miller, Thermospheric winds at high latitudes from chemical release observations, J. Geophys. Res., 87, $1633-1647,1982$.

Hernandez, G., Measurements of temperatures and winds by remote Fabry-Perot spectrometry, Opt. Eng., 19, 518-532, 1980.

Hernandez, G., Analytical description of a Fabry-Perot spectrometer, 6, Minimum number of samples required in the determination of Doppler widths and shifts, Appl. Opt., 21, 1695, 1982.

Hernandez, G., and R. G. Roble, Thermospheric dynamics investigations with very high resolution spectrometers, Appl. Opt., 18, 3376-3385, 1979.

Hoffman, R. A., and E. R. Schmerling, Dynamics Explorer program: An overview, Space Sci. Instrum., 5, 345-348, 1981.

Kelly, J. D., and V. B. Wickwar, Radar measurements of high-latitude ion composition between 140 and $300 \mathrm{~km}$ altitude, J. Geophys. Res., $86,7616-7626,1981$.

Killeen, T. L., and P. B. Hays, Doppler line profile analysis for a multichannel Fabry-Perot interferometer, Appl. Opt., 23, 612-620, 1984.

Killeen, T. L., P. B. Hays, N. W. Spencer, and L. E. Wharton, Neutral winds in the polar thermosphere as measured from Dynamics Explorer, Geophys. Res. Lett., 9, 957-960, 1982.

Killeen, T. L., P. B. Hays, N. W. Spencer, and L. E. Wharton, Neutral winds in the polar thermosphere as measured from Dynamics Explorer, Adv. Space Res., 2, 133-136, 1983.

King-Hele, D. G., and R. R. Allan, The rotational speed of the upper atmosphere, Space Sci. Rev., 6, 248-272, 1966.

Mayr, H. G., and I. Harris, $F$ region dynamics, Rev. Geophys. Space Phys., 17, 492-510, 1979.

Mayr, H. G., I. Harris, and N. W. Spencer, Some properties of upper atmosphere dynamics, Rev. Geophys. Space Phys., 16, 539-565, 1978.

Meriwether, J. W., Jr., Observations of thermospheric dynamics at high latitudes from ground and space, Radio Sci., 18, 1035-1052, 1983.

Meriwether, J. W., Jr., J. P. Heppner, J. D. Stolarik, and E. M. Wescott, Neutral winds above $200 \mathrm{~km}$ at high latitudes, $J$. Geophys. Res., 78, 6643-6661, 1973.

Meriwether, J. W., Jr., C. A. Tepley, S. A. Price, P. B. Hays, and L. L. Cogger, Remote ground-based observations of terrestrial arrglow emissions and thermospheric dynamics at Calgary, Alberta, Canada, Opt. Eng., 22, 128-131, 1983.

Nagy, A. F., R. J. Cicerone, P. B. Hays, K. D. McWatters, J. W. Meriwether, A. E. Belon, and C. L. Rino, Simultaneous measurement of ion and neutral motions by radar and optical techniques, Radio Sci., 9, 315-321, 1974.

Rees, D., T. J. Fuller-Rowell, and R. W. Smith, Measurements of high latitude thermospheric winds by rocket and ground-based techniques and their interpretation using a three-dimensional, timedependent dynamical model, Planet. Space Sci., 28, 919-932, 1980.

Rees, D., P. A. Rounce, P. Charleton, T. J. Fuller-Rowell, I. McWhirter, and K. Smith, Thermospheric winds during the energy budget campaign: Ground-based Fabry-Perot observations supported by dynamical simulations with a three-dimensional, time-dependent thermospheric model, J. Geophys., 50, 202-211, 1982.

Rees, M. H., Auroral electrons, Space Sci. Rev., 14, 413-441, 1969.

Richmond, A. D., Gravity wave generation, propagation, and dissipation in the thermosphere, J. Geophys. Res., 83, 4131-4145, 1978.

Richmond, A. D., Large-amplitude gravity wave energy production and dissipation in the thermosphere, J. Geophys. Res., 84, 1385$1389,1979$.

Roble, R. G., and M. H. Rees, Time-dependent studies of the aurora: Effects of particle precipitation on the dynamic morphology of ionospheric and atmospheric properties, Planet Space Sci., 39, 503$511,1977$.

Roble, R. G., R. E. Dickinson, and E. C. Ridley, Global circulation and temperature structure of thermosphere with high-latitude plasma convection, $J$. Geophys. Res., 87, 1599-1614, 1982.

Roble, R. G., R. E. Dickinson, E. C. Ridley, B. A. Emery, P. B. Hays, T. L. Killeen, and N. W. Spencer, The high latitude circulation and temperature structure of the thermosphere near solstice, Planet. Space Sci., 31, 1479-1499, 1983.

Schmitt, G. A., V. J. Abreu, and P. B. Hays, Non-thermal $O\left({ }^{1} D\right)$ produced by dissociative recombination of $\mathrm{O}_{2}^{+}:$A theoretical model and observational results, Planet. Space Sci., 29, 1095-1099, 1981.

Schmitt, G. A., V. J. Abreu, and P. B. Hays, Line shape of the nonthermal 6300-A O $\left({ }^{1} D\right)$, Planet. Space Sci., 30, 457-461, 1982.

Schunk, R. W., and J. C. G. Walker, The theory of charged particle temperatures in the upper atmosphere, in Progress in High Temperature Physics and Chemistry, vol. 5, edited by C. A. Rouse, Pergamon, New York, 1973.

Sharp, W. E., D. Ortland, and R. Cageao, Concerning sources of $O\left({ }^{1} D\right)$ in aurora: Electron impact and dissociative recombination, J. Geophys. Res., 88, 3229-3232, 1983.

Spencer, N. W., L. E. Wharton, H. B. Niemann, A. E. Hedin, G. R. Carignan, and J. C. Maurer, The Dynamics Explorer wind and temperature spectrometer, Space Sci. Instrum., 5, 417-418, 1981.

Spencer, N. W., L. E. Wharton, G. R. Carignan, and J. C. Maurer, Thermospheric zonal winds, vertical motions, and temperature as measured from Dynamics Explorer, Geophys. Res. Lett., 9, 953-956, 1982

Stoffregen, $\mathrm{W}$., The anomaly of the neutral wind at a height of about $200 \mathrm{~km}$ at high latitudes, in Magnetosphere-Ionosphere Interactions, edited by K. Folkestad, pp. 83-86, Universitetsforlaget, Oslo, Norway, 1972.

Straus, J. M., Dynamics of the thermosphere at high latitudes, Rev. Geophys. Space Phys., 16, 183-194, 1978. 
Swider, W., and R. S. Narcisi, Auroral E-region: Ion composition and nitric oxide, Planet. Space Sci., 25, 103-116, 1977.

Wickwar, V. B., L. L. Cogger, and H. C. Carlson, The $6300-\AA O\left({ }^{1} D\right)$ airglow and dissociative recombination, Planet. Space Sci., 22, 709724, 1974.

Zipoy, D. M., Fabry-Perot inversion algorithm, App. Opt., 18, 19881995, 1979.
P. B. Hays, J. W. Meriwether, Jr., and A. F. Nagy, Space Physics Research Laboratory, University of Michigan, Ann Arbor, MI 48109.

V. B. Wickwar, SRI International, 333 Ravenswood Avenue, Menlo Park, CA 94025 .

(Received March 19, 1984;

accepted May 25, 1984.) 